Research Article

\title{
The Influences of Bladder Properties on the Working Performance of the Multibladder-Type Inflatable Anchor
}

\author{
Wen Xiang Peng, ${ }^{1}$ Ming Kai Xu, ${ }^{1}$ Yi Fan Chen $\mathbb{D}^{,},{ }^{2}$ Bo Yuan, ${ }^{1}$ Zhuo Yang, ${ }^{3}$ and Hang Lin $\mathbb{D}^{2}$ \\ ${ }^{1}$ School of Geosciences and Info-physics, Central South University, Changsha, Hunan 410083, China \\ ${ }^{2}$ School of Resources and Safety Engineering, Central South University, Changsha, Hunan 410083, China \\ ${ }^{3}$ Guangzhou Institute of Building Science CO.,LTD, Guangzhou 510440, China
}

Correspondence should be addressed to Yi Fan Chen; 1051361824@qq.com

Received 12 May 2021; Accepted 18 August 2021; Published 30 August 2021

Academic Editor: Jian Ji

Copyright (c) 2021 Wen Xiang Peng et al. This is an open access article distributed under the Creative Commons Attribution License, which permits unrestricted use, distribution, and reproduction in any medium, provided the original work is properly cited.

\begin{abstract}
Due to the high bearing capacity and better controllability of bladder parameters, the multibladder-type inflatable anchor shows a great application prospect in the engineering construction in soft soil areas. In this study, based on a soft soil foundation pit project in Guangzhou Province, China, the multibladder-type inflatable anchor was applied to the engineering practice for the first time, and the working characteristics of the multibladder-type inflatable anchor were analyzed and discussed through field experiments. Primarily, the optimization design and experimental facility of the multibladder-type inflatable anchor were introduced in detail to realize the refinement and perfection of the anchorage technological process. Besides, the influence degrees of the bladder number, diameter, thickness, space, and length on the bearing characteristics and deformation control of the anchor were studied by using the control variable method, as well as the influencing mechanisms. Subsequently, the advantages of the multibladdertype inflatable anchor were presented by comparing its anchoring efficacy with that of the traditional grouting anchor. Ultimately, the analysis results were used to verify the reliability of the multibladder-type inflatable anchor and provide the experimental basis for its popularization and application.
\end{abstract}

\section{Introduction}

Anchorage technology can enhance the strength and selfstability of rock and soil mass, so as to achieve the construction purpose and safety requirements [1-4]. It has been recognized internationally since 1872 when the rebar was firstly applied to reinforce the rock slope of the open shale mine in North Wales of England and produced expectant results [5] and was first proposed in the patent application in 1913 [6]. As an economical and effective method [7], it was widely used in the projects of slope reinforcement, foundation pit support, tunnel, foundation and antifloating structure, anti-overturning structure, dam, roadway support, and so on [8-12]. In recent years, the modernization progress is advancing faster and faster, and underground engineering constructions continually emerge [13], accompanied by complex terrain, poor geological conditions, and changeable surrounding environment, which brings complex challenges and requirements to the anchorage technology of geotechnical engineering and inspires scholars and experts to carry out deep investigations on the anchorage form, anchorage mechanism, anchorage structures, construction technology, and experimental methods.

It is when the well-known interregional water transfer project "the Snowy Mountains Scheme" was constructed in Australia, the anchorage mechanism was scientifically and systematically studied for the first time, which laid the theoretical foundation of anchorage as a permanent support technology in rock engineering [14-16]. Subsequently, Rabcewicz, Jacob, and Panek et al. successively put forward the foundation support theories such as suspension, composite beam, and composite arch [17]. In the 1980s, the United States, South Africa, Australia, the 
former Soviet Union, and other countries have developed the support structure of the flexible anchor, active prestressed bolt, and high-strength anchor cable in accordance with the unfavorable geological conditions such as deep high stress and weak surrounding rock encountered in mining engineering [18]. Furthermore, Freeman [19] introduced the concepts of neutral point, critical length, and anchorage length. The study of Li et al. [20] showed that there was a linear relationship between critical anchorage length and mortar strength. Srivastava and Singh [21] studied the effect of the passive anchor on the failure mode of crack rock samples and the enhancement of elastic modulus and strength. Hass [22] pointed out that the inclined anchor had stronger effects on the shear strength improvement of the jointed rock than the vertical anchor. Barton [23] concluded that the best anchoring effect emerged when the anchoring angle ranged from $35^{\circ}$ to $60^{\circ}$.

In conventional engineering applications, the anchorage forms are usually divided into two types [24-31]. One of them includes slit wedge tubing anchor and swelling anchor and plays the anchoring role through the friction between the anchorage section and the surrounding rock mass. The anchoring efficiency of the other is mainly achieved via the bonding force generated from the interaction of the anchor body, surrounding rock, and cementing material, such as cement mortar anchor and resin anchor. In addition, the new types of anchor, such as inflatable anchor [32-35], yielding anchor [36, 37], and hot melting-retrievable anchor [38], also promote extensive research studies on the engineering design and the anchorage force transmission mode, wherein the multibladder-type inflatable anchor [39-42] is a kind of special anchor derived from the inflatable anchor, which not only inherits the high bearing capacity of the inflatable bolt but also can enhance the controllability by adjusting the bladder parameters, indicating obvious superiorities in the application of underground engineering in the offshore region where the soft soil layer is widely encountered.

However, the design and production of the multibladder-type inflatable anchor are still in the stage of continuous exploration and improvement. During the process of indoor model tests and field experiments conducted by predecessors [43], air leakage, water leakage, and other undesirable phenomena which resulted from pressure instability and poor sealing effect still existed, which lead to the weakness of bearing capacity, poor displacement control, and distortion of experimental data. Therefore, supported by a soft soil foundation pit project in Guangzhou Province, China, a series of field pullout experiments were carried out on the independently developed and designed multibladder-type inflatable anchor to test its bearing capacity and deformation control in this study, and the results were compared with those of the traditional grouting anchor. Besides, the influence analysis of different bladder parameters on the working characteristics of this anchor was implemented to explore the feasibility of its application in engineering.

\section{Field Experiments of the Multibladder-Type Inflatable Anchor in the Soft Soil Foundation Pit}

2.1. Geological Conditions of the Experimental Site. The experimental site was provided by Guangzhou Architectural Research Institute Co. Ltd., and relied on the South Plot Project of the Central Intersection and Communication Center, which is located at the tip of Lingshan Island in Mingzhu Bay Development Zone, Nansha New District, Guangzhou city. The surrounding area is paved with planned roads whose designed elevation is about $8.0 \mathrm{~m}$, and the interior of the site is flat (the current elevation is about $4.0 \mathrm{~m}$ ) and covers an area of $40,752 \mathrm{~m}^{3}$. The project importance is grade 1 , so does the foundation and safety level of the foundation pit support, and the importance coefficient of the foundation pit side wall is 1.1. The west side of the site was selected for the experiments where the depth of the foundation pit is $9.7 \mathrm{~m}$. The two-floor basement was filled with piles of $26.53 \mathrm{~m}$ in length and two rows of prestressed anchor cables, and the three-axis mixing pile was used as the water curtain. The site area is an alluvial landform of estuarine delta in the South Asian tropical monsoon climate zone, with abundant rainfall and sunshine in summer. The experimental site was originally a fishpond and was filled with soil and prepressured by vacuum for soft soil foundation treatment. There is a large amount of water on the low-lying ground, and the surroundings are municipal roads under construction in the completion acceptance stage.

According to the detailed survey report, the strata in the site area (from top to bottom) are as follows: I filling $\left(Q^{m l}\right)$ : I-1 cohesive plain filling and I-2 grinding plain filling; II alluvial soil $\left(Q^{a l}\right)$ : II-1 muddy soil, II-2 mud, II-3 medium sand, and II-4 muddy soil, II-5 coarse sand; III residual soil $\left(Q^{e l}\right)$; IV bedrock $\left(\gamma_{5}{ }^{3}\right)$ : IV-1 fully weathered layer, IV-2 heavily weathered layer, and IV-3 subweathered layer. No fault structure emerges, and the foundation is stable. The groundwater type belongs to pore water, which is shallow, abundant, and slightly corrosive. The layer formation of the supporting surface of the west experimental section (from top to bottom) is as follows: I-2 grinding plain filling (incompact), II-1 muddy soil (flow-plastic), II-2 mud (flowplastic), II-3 medium sand, II-4 muddy soil (flow-plastic), II5 coarse sand (medium dense), and IV bedrock, as shown in Figure 1.

2.2. Experimental Facilities. The fabrication and installation materials of the multibladder-type inflatable anchor are available in [41], as well as the development and structure design. In practical experiments, the anchor will be inserted into the side wall of the foundation pit by the trepanning of the crawler anchor rope drill with the carbide bit [44] (see Figure 2), which can be categorized as small rotary rock drill common in geotechnical engineering. It has fast driving speed and is adjustable in drilling angle. The specific technical parameters are shown in Table 1.

Weld the threaded rebar $(600 \mathrm{~mm}$ in length and $22 \mathrm{~mm}$ in diameter) at the distance of $200 \mathrm{~mm}$ from the end of the 


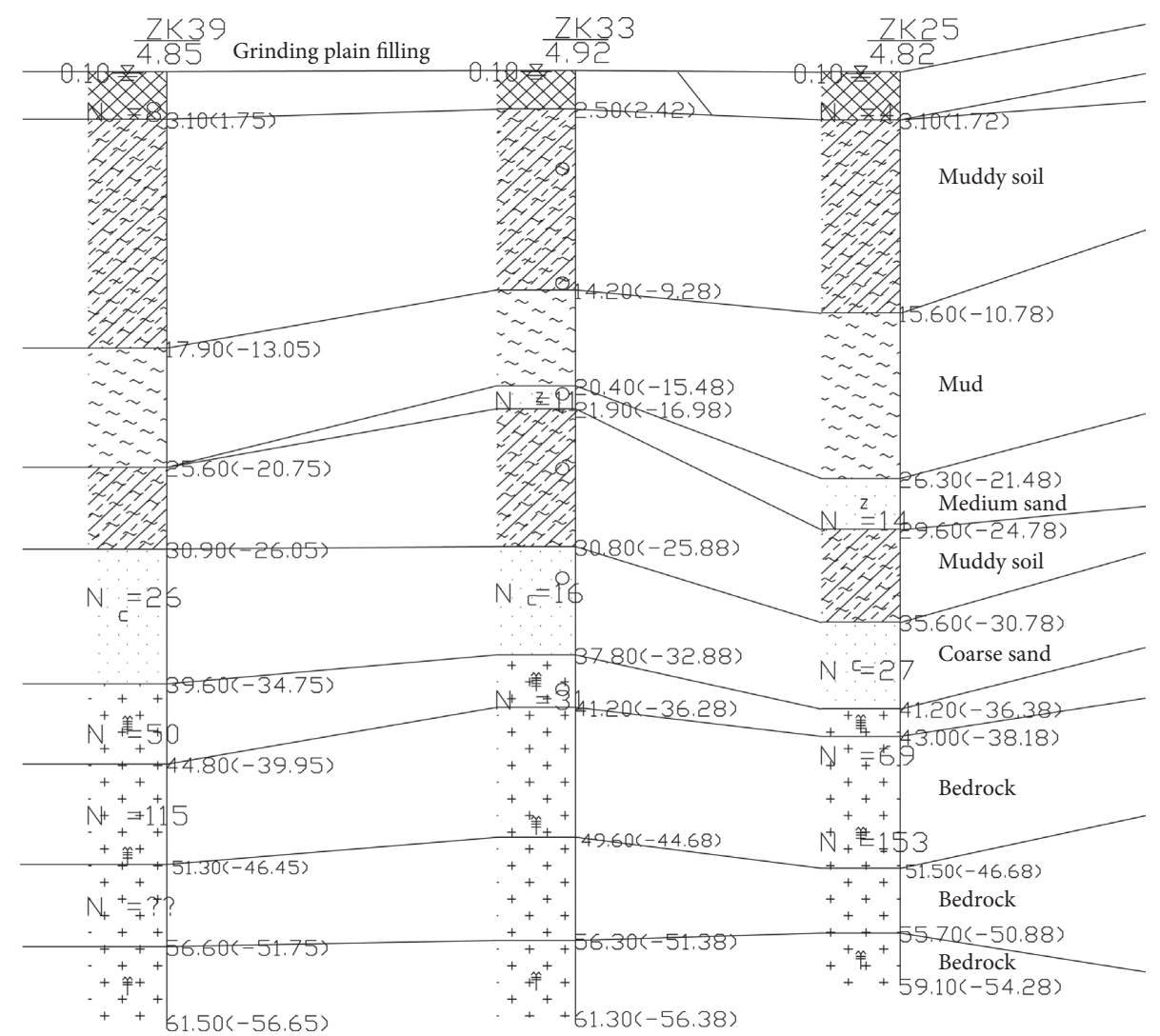

FIgURE 1: The stratigraphic texture of the experimental site.

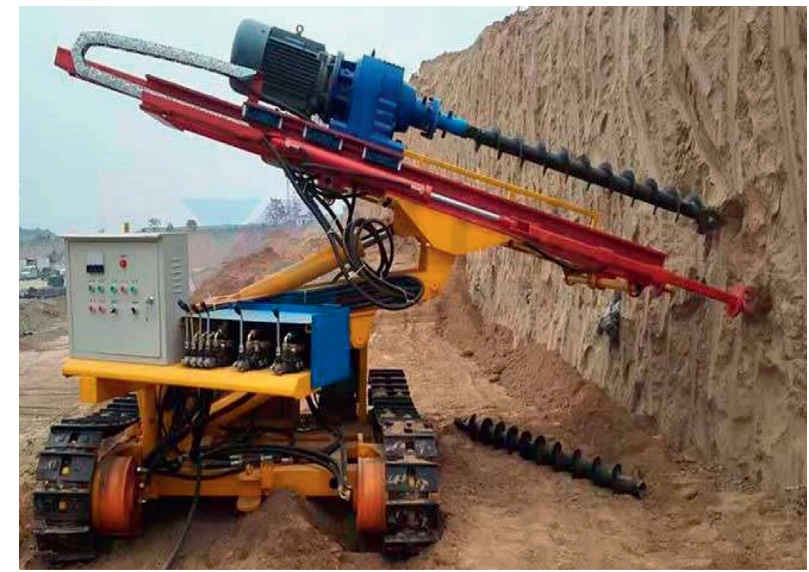

FIgURE 2: Field trepanning.

anchor to fabricate the auxiliary device of the pullout experiment, namely, steel alignment bracket $(200 \mathrm{~mm} \times 200 \mathrm{~mm} \times 400 \mathrm{~mm}$ in dimension). The specific operations can be realized by using the DC welding machine, and the physical product is shown in Figure 3. The pullout experimental device used in this study is composed of an anchor pullout tester and dial indicator which are, respectively, designed to measure anchorage force and displacement [45], while the anchor pullout tester consists of a digital display manometer, high-pressure oil pipe, hydraulic cylinder, and wobble pump. Specifically, the diameter of the center hole of the oil cylinder is $27 \mathrm{~mm}$, the cylinder stroke is $60 \mathrm{~mm}$, the measurement range is $0-100 \mathrm{kN}$, and the resolution is $0.01 \mathrm{kN}$. Besides, the measurement range of the dial indicator is $0-10 \mathrm{~mm}$, with the dividing value of $0.01 \mathrm{~mm}$.

Since it is difficult to control the expansion shape of the bladder in soil mass during current research studies and it is still unknown that how much air pressure is sufficient to meet the design requirements of bladder volume, the water injection method was applied to the multibladder-type inflatable anchor, instead of air inflation. 
TABLE 1: The technical parameters of the crawler anchor rope drill.

\begin{tabular}{lcccccr}
\hline Type & Drilling diameter $(\mathrm{mm})$ & Drilling depth $(\mathrm{m})$ & Drilling angle $\left(^{\circ}\right)$ & Motor phase & Weight $(\mathrm{kg})$ & Boundary dimension $(\mathrm{mm})$ \\
\hline $\begin{array}{l}\text { TS- } \\
\text { 22A }\end{array}$ & $80-200$ & $0-50$ & $0-135$ & $\begin{array}{c}\text { Three-phase } \\
\text { current }\end{array}$ & 3500 & $2020 \times 2260 \times 3250$ \\
\hline
\end{tabular}

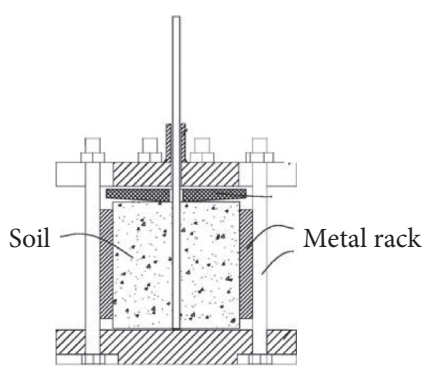

(a)

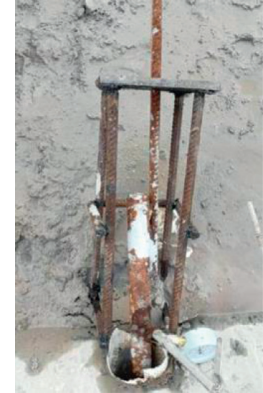

(b)

Figure 3: The auxiliary device of the field pullout experiment. (a) The schematic diagram of the auxiliary device in the field pullout experiment. (b) Field installation of the auxiliary device in the field pullout experiment.

2.3. Field Experiment Contents and Arrangements. The task of the experiments is to investigate the influence of bladder parameters, length, thickness, diameter, number, and space, on the bearing characteristics and deformation control capability of the multibladder-type inflatable anchor (see Figure 4) and obtain the optimal collocation of bladder parameters. It should be noted that the bladder thickness means the thickness of the bladder wall, which can also be regarded as the thickness of rubber material producing the bladder. Therefore, the experimental scheme organized by the control variable method is shown in Table 2 .

A brief introduction of the experimental process (anchor production-trepanning location-angle determination-drilling and clearing-anchor placement-water injection-pullout experiments-anchor recycle) is presented as shown in Figure 5.

Some considerations in the construction methods and technical requirements are as follows:

(1) Drilling and clearing: select the supporting section (already constructed by the pile anchor), locate the reserved point between the adjacent anchor cables of the crown beam, and trepan the hole by using the crawler anchor cable drill. Considering the structural particularity of the anchor and the characteristics of muddy soil (easy to collapse and shrink), the pressure water drilling was adopted. During the process, water flushing will discharge the soil debris out of the hole until water flows without turbidity. Note that the diameter of the drilling hole is $110 \mathrm{~mm}$, the depth is about $12.5 \mathrm{~m}$ (greater than the design length), the dip angle is $15^{\circ}$, and the horizontal spacing is $2.0 \mathrm{~m}$.

(2) Anchor placement: due to the limitation of the site space and handling conditions, the tower crane was used to assist the transfer of the anchor, which was pushed into the borehole through the crawler cable drill to complete the placement process, instead of the original manual handling and lowering method. The anchor must extend $300 \mathrm{~mm}$ from the side wall for later detection and test.

(3) Water injection: before the experiment, the water injection volumes of the anchor with different bladders and numbers under the condition of complete expansion were calculated. The water injection volume is composed of hollow volume of the anchor and expanded volume of the bladder (approximately ellipsoid). Connect the pumping pipe of the grouting pump to the plastic cylinder with a diameter of $540 \mathrm{~mm}$ and the injecting pipe to the anchor control valve, and complete the water injection according to the calculated volume, which can be solved by equations (1)-(3). Water injection volume of each anchor is shown in Table 3. After water injection is completed, close the anchor control valve, and disconnect the pump.

$$
\begin{aligned}
V_{\text {injection }} & =V_{\text {anchor }}+V_{\text {bladder }} \\
V_{\text {anchor }} & =\pi r^{2} l \\
V_{\text {bladder }} & =\frac{4}{3} \pi a^{2} b-V_{\text {coincide }}
\end{aligned}
$$

where $V_{\text {anchor }}$ is the hollow volume of the anchor; $V_{\text {bladder }}$ is the expanded volume of the bladder; $r$ is the anchor inner diameter, and $r=22 \mathrm{~mm}$; $l$ is the anchor length, and $l=12 \mathrm{~m} ; a$ is the maximum radius of the bladder, and $a=75 \mathrm{~mm}$ or $65 \mathrm{~mm}$; $b$ is the half of bladder length, $b=250 \mathrm{~mm}, 375 \mathrm{~mm}$, or $500 \mathrm{~mm}$; and $V_{\text {coincide }}$ is the overlapped volume of the bladder and anchor.

(4) Pullout experiments: make the steel alignment bracket pass through the threaded rebar welded to 


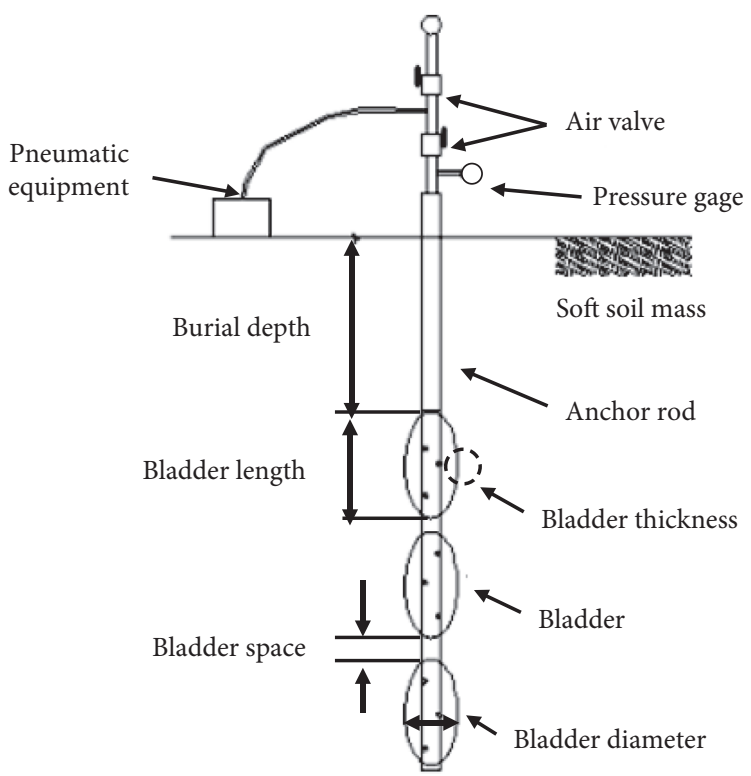

Figure 4: The schematic diagram of the multibladder-type inflatable anchor.

the end of the anchor, place the hydraulic jack close to the support plate, and connect the displacement meter and pressure gauge. Then, the step load was applied ( $2 \mathrm{kN}$ for each step), and the bearing capacity and displacement were recorded until anchorage failure (see Figure 3), which occurs when the gauge pointer suddenly decreases or the displacement is twice to that under the previous loading stage [46]. To be specific, when the value of displacement is twice as much as the previous displacement accumulation or the value of the pressure gauge is significantly reduced or the hydraulic jack cannot be continuously pressurized, the anchor is considered as reaching the failure standard, and the experiment will be stopped.

(5) Anchor recycle: after the experiment completion, open the control valve to drain water, use the excavator to pull out the anchor, and check its integrity, including anchor fracture degree, bladder, and seal damage degree.

\section{Analysis of Experimental Results}

As previously described, the benchmark values of the main influencing factors were determined, and the physical properties of the experimental site, soil, and bladder were generally considered. During each loading process, the displacement was recorded three times, as well as its increment.

3.1. Bladder Length. According to Table 2, the results of experiments 1, 2, and 3 were selected for analysis and discussion. Comparison of the pulling resistance of the multibladder-type inflatable anchor corresponding to $500 \mathrm{~mm}$, $750 \mathrm{~mm}$, and $1000 \mathrm{~mm}$ bladder lengths is shown in Figure 6.
During the experiment, the displacement keeps increasing, then the curve reaches the peak, the expansion bolt is pulled out, so the subsequent curve cannot be obtained. So, in fact, the value shown at the end of the curve is the peak intensity. So, the ultimate pullout stress/displacement can be defined to be the last point values. It can be known that the ultimate pulling resistance of the anchor is increasing with the increase of the bladder length, but the increasing trend is not obvious, and the increasing rate is weakening. Concretely, when the bladder length increases from $500 \mathrm{~mm}$ to $750 \mathrm{~mm}$, the ultimate pulling resistance increases by $23 \%$, and it increases by $8 \%$ for the length increasing from $750 \mathrm{~mm}$ to $1000 \mathrm{~mm}$. As for the ultimate displacement of the anchor, the variation is also inconspicuous, and it declines by $8 \%$ and then climbs up by $5 \%$ with the increase of bladder length. In summary, the bladder length variation shows no significant influence on the ultimate bearing capacity and deformation control of the anchor.

The reason is that the increase of bladder length enlarges the contact area between the bladder and soil, and the lateral friction of the bladder presents a negatively exponential increasing trend along the stress direction of the anchor. When the bladder length reaches the threshold, only the frictional resistance of the front part of the expanded bladder works, which proves that the positive influence of the bladder length is limited. Especially for soft soil, the effective bladder length is closely related to the physical and mechanical properties of soil materials.

3.2. Bladder Thickness. Under the condition that bladder length, number, space, and diameter were determined, the results of experiments 1, 4, and 5 were selected for analysis and discussion. In Figure 7, the ultimate pulling resistance of the anchor is remarkably increased with the increase of bladder thickness, for it increases by $21 \%$ when the bladder 
TABLE 2: The pullout experiment design of the multibladder-type inflatable anchor.

\begin{tabular}{|c|c|c|c|c|c|c|c|}
\hline Number & $\begin{array}{l}\text { Bladder length } \\
(\mathrm{mm})\end{array}$ & $\begin{array}{l}\text { Bladder thickness } \\
(\mathrm{mm})\end{array}$ & $\begin{array}{l}\text { Bladder } \\
\text { number }\end{array}$ & $\begin{array}{l}\text { Bladder space } \\
(\mathrm{mm})\end{array}$ & $\begin{array}{l}\text { Bladder diameter } \\
(\mathrm{mm})\end{array}$ & $\begin{array}{c}\text { Ultimate load } \\
(\mathrm{kN})\end{array}$ & $\begin{array}{c}\text { Ultimate } \\
\text { displacement }(\mathrm{mm})\end{array}$ \\
\hline 1 & 500 & 4 & 4 & 500 & 150 & 35.57 & 93.46 \\
\hline 2 & 750 & 4 & 4 & 500 & 150 & 43.87 & 86.13 \\
\hline 3 & 1000 & 4 & 4 & 500 & 150 & 47.35 & 90.13 \\
\hline 4 & 500 & 2 & 4 & 500 & 150 & 29.47 & 119.73 \\
\hline 5 & 500 & 6 & 4 & 500 & 150 & 48.37 & 89.09 \\
\hline 6 & 500 & 4 & 5 & 500 & 150 & 37.41 & 81.32 \\
\hline 7 & 500 & 4 & 6 & 500 & 150 & 41.05 & 70.34 \\
\hline 8 & 500 & 4 & 4 & 750 & 150 & 38.14 & 86.73 \\
\hline 9 & 500 & 4 & 4 & 1000 & 150 & 40.29 & 82.38 \\
\hline 10 & 500 & 4 & 4 & 500 & 200 & 46.73 & 68.35 \\
\hline 11 & 500 & 4 & 4 & 500 & 250 & 55.08 & 53.97 \\
\hline
\end{tabular}

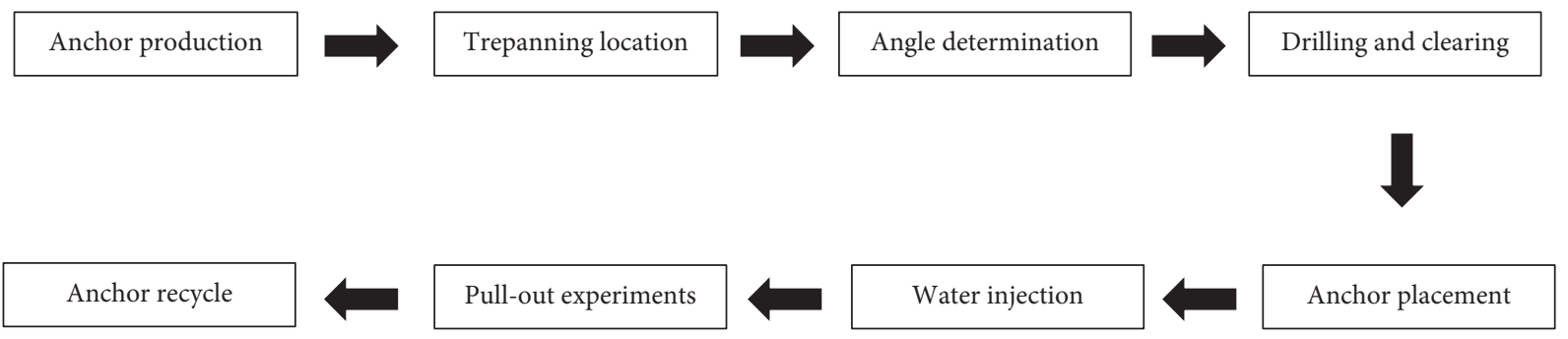

FIgURE 5: The experimental process.

TABLE 3: Water injection calculating volume of the multibladder-type inflatable anchor.

\begin{tabular}{lcccc}
\hline Number & Bladder length $(\mathrm{mm})$ & Bladder number & Bladder diameter $(\mathrm{mm})$ & ${\text { Water injection volume }\left(\mathrm{m}^{3}\right)}^{3}$ \\
\hline 1 & 500 & 4 & 150 & 0.0456 \\
2 & 1000 & 4 & 150 & 0.0764 \\
3 & 500 & 4 & 130 & 0.0370 \\
4 & 500 & 5 & 150 & 0.0524 \\
5 & 500 & 6 & 150 & 0.0592 \\
\hline
\end{tabular}

thickens from $2 \mathrm{~mm}$ to $4 \mathrm{~mm}$ and increases by $36 \%$ from $4 \mathrm{~mm}$ to $6 \mathrm{~mm}$. At the same time, the corresponding ultimate displacement, respectively, decreases by $28 \%$ and $5 \%$. As a single parameter index, the bladder thickness shows more influences than bladder length in controlling anchor deformation and increasing ultimate pulling strength.

When the expanding volume is similar, the thicker bladder has greater elasticity modulus and can bear greater lateral friction, while contrary experimental findings may be obtained in the case of similar air pressure in the bladder since the thicker bladder will reduce the expanding volume and provide smaller pulling resistance. In this paper, due to the limitation of field conditions, the comparative experiments of air pressure and thickness were not considered.

3.3. Bladder Number. Similarly, the results of experiments 1, 6 , and 7 were selected, which are plotted in Figure 8. Obviously, the more the bladder number, the greater the ultimate pulling resistance of the anchor. To be specific, the pulling resistance increases by $5 \%$ and $9 \%$ with the increase of the bladder number, while the ultimate displacement decreases by $13 \%$ and $15 \%$, which demonstrates that the bladder number has different effects on the improvement of ultimate pulling resistance and the control of anchor deformation and focuses more on the latter.

Despite there is no dramatic change in the value of bearing capacity and deformation control, the enhancing effect is obvious. When the bladder number increases, the function of lateral friction will be reduced.

3.4. Bladder Space. The results of experiments 1, 8, and 9 illustrate the influence of the bladder space on the working characteristics of the multibladder-type inflatable anchor, which is slight according to Figure 9. Both variations are inconspicuous, less than $10 \%$ for the pulling resistance, and about $14 \%$ for the ultimate displacement.

Although the increase of the bladder space shows a positive effect on improving the ultimate pulling force and controlling the anchor deformation, such improvement is less efficient. Therefore, it can be inferred that there may be an effective space, and it will produce a reverse effect when exceeding the space [47], which can be explained with that the working area of the bladder is limited, and the effect will be reduced once the bladder space is beyond the area. 


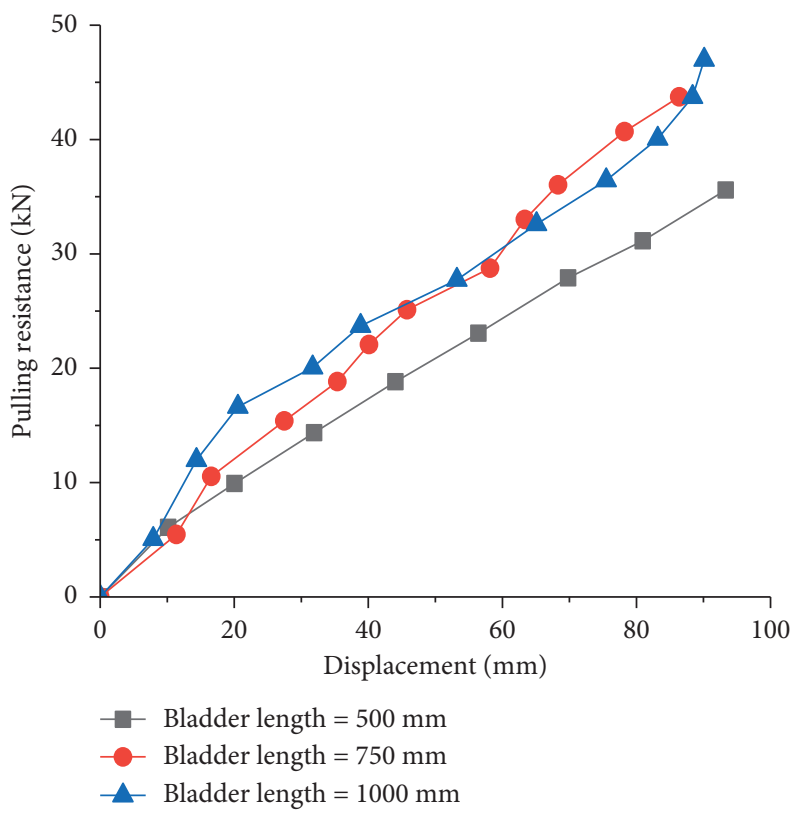

FIGURE 6: The pulling force vs. displacement relationship under different bladder length conditions.

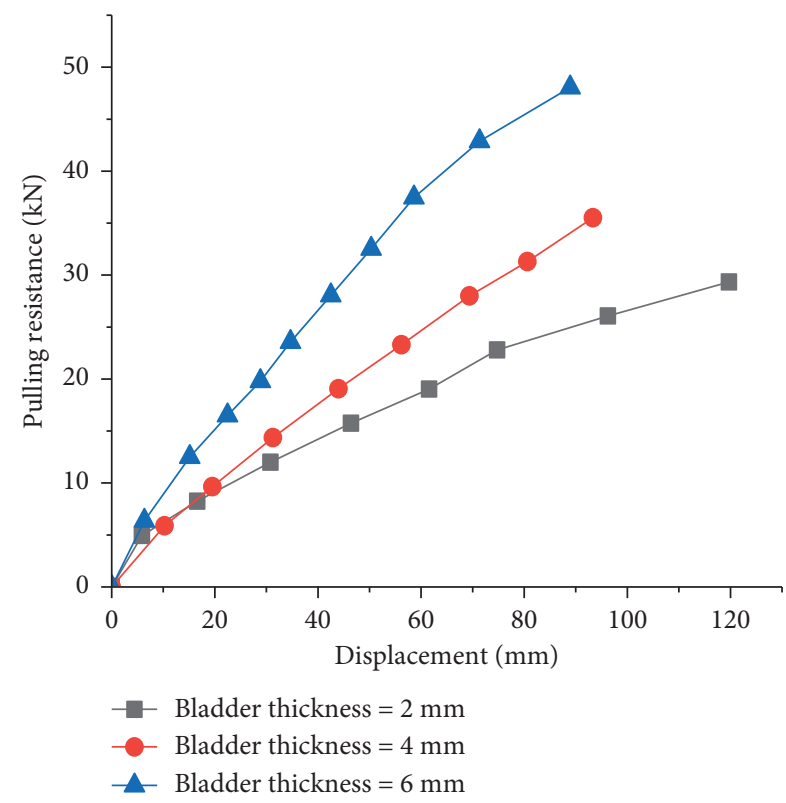

Figure 7: The pulling force vs. displacement relationship under different bladder thickness conditions.

3.5. Bladder Diameter. Also, the results of experiments 1, 10, and 11 were used to explore the influence of bladder diameter. As described in Figure 10, with the increase of bladder diameter, the ultimate pulling resistance is notably strengthened (31\% when diameter changes from $150 \mathrm{~mm}$ to $200 \mathrm{~mm}$ and $18 \%$ from $200 \mathrm{~mm}$ to $250 \mathrm{~mm}$ ), and the ultimate displacement is significantly decreased (the corresponding decreasing proportions are $27 \%$ and $21 \%$ ).

In essence, the change in diameter is, namely, the change in the expansion volume, and the bearing capacity and deformation control effect of the anchor are improved obviously when the expansion volume increases, which is coincident with the existing research conclusions. Besides, the increase in the expansion volume augments the area of interaction with soft soil around the bladder, accompanied by the magnification of lateral friction and terminal friction of the anchor, and, therefore, is helpful to improve the ultimate pulling force and control the anchor deformation.

\section{Comparative Experiment with the Conventional Grouting Anchor}

By determining bladder number $=4$, bladder space $=500 \mathrm{~mm}$, bladder diameter $=150 \mathrm{~mm}$, bladder thickness $=4 \mathrm{~mm}$, and bladder length $=500 \mathrm{~mm}$, the comparative experiment between the multibladder-type inflatable anchor and conventional grouting anchor with $4 \mathrm{~m}$ anchorage section (the original support form of the experimental site) was implemented.

Based on Table 4 and Figure 11, under the specific bladder parameter collocation, the ultimate pulling resistance of the multibladder-type inflatable anchor is 1.37 times to that of the conventional grouting anchor, while the ultimate displacement of the former is 1.17 times to that of the latter, which means the multibladder-type inflatable anchor has more advantages in bearing capacity and is weaker in deformation control of the anchor. On the one hand, the design of multiple bladders greatly increased the terminal resistance of the anchor since bladder expansion compresses soil to deform, improving soil properties. On the other hand, the anchorage section of the multibladder-type inflatable anchor is composed of butyl rubber film and water, which is flexible, and it is more deformed under pulling load comparing to the cement mortar anchorage section of the conventional grouting anchor. Finally, to realize the effective displacement control of the multibladder-type inflatable 


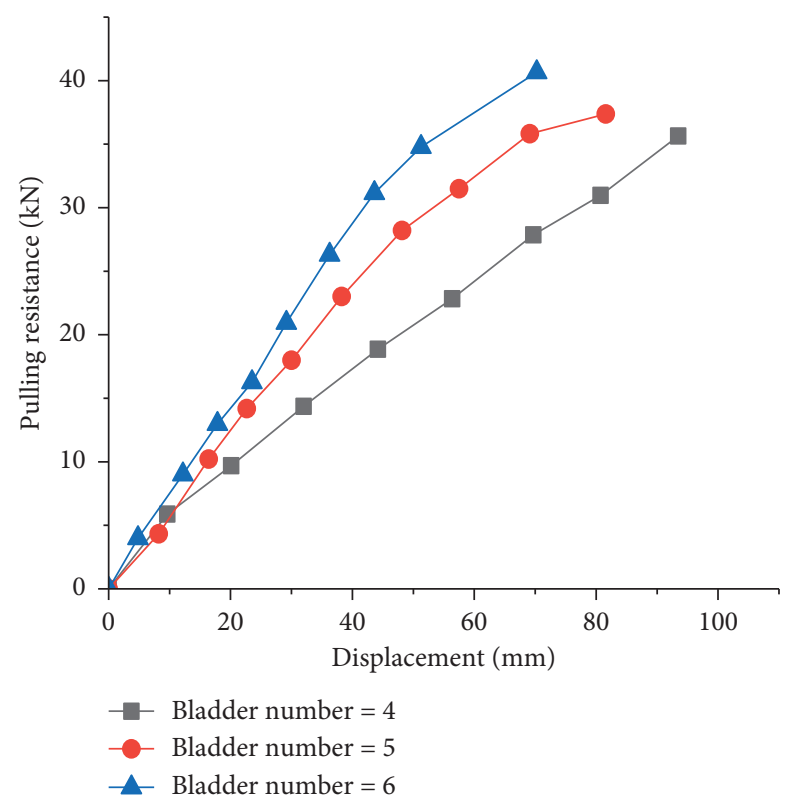

FIGURE 8: The pulling force vs. displacement relationship under different bladder number conditions.

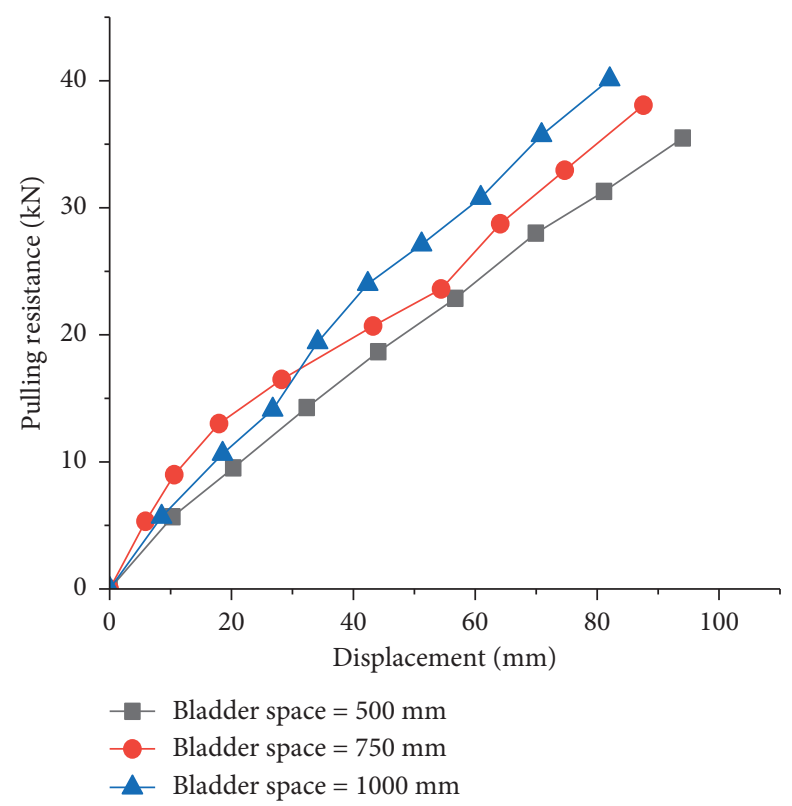

FIgURE 9: The pulling force vs. displacement relationship under different bladder space conditions. 


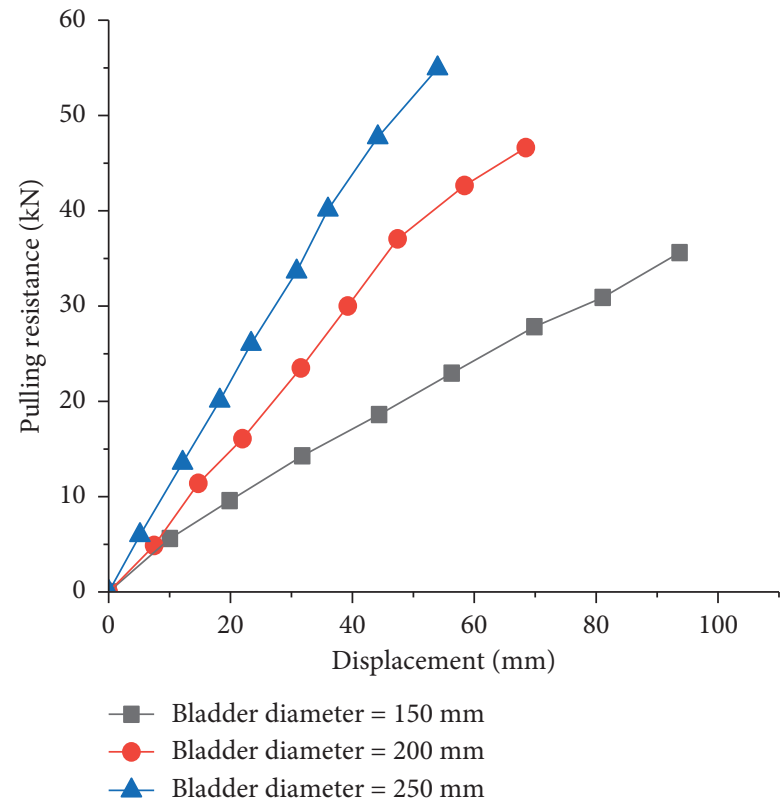

Figure 10: The pulling force vs. displacement relationship under different bladder diameter conditions.

TABLE 4: Comparative result of bearing characteristics between the multibladder-type inflatable anchor and conventional grouting anchor.

\begin{tabular}{lcc}
\hline Anchor type & Ultimate pulling resistance $(\mathrm{kN})$ & Ultimate displacement $(\mathrm{mm})$ \\
\hline The multibladder-type inflatable anchor & 35.57 & 93.46 \\
The conventional grouting anchor & 26.03 & 79.82 \\
\hline
\end{tabular}

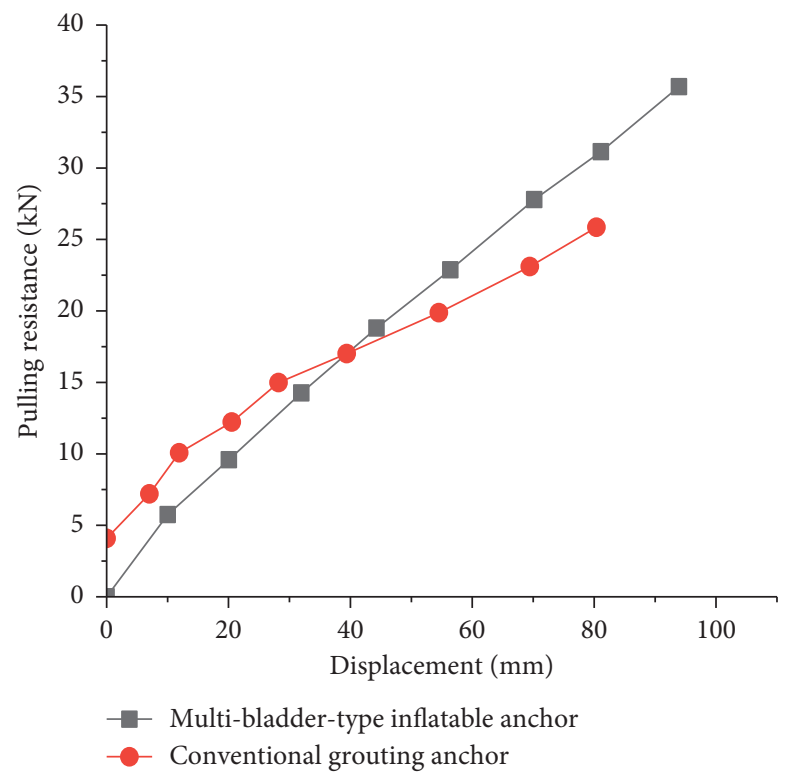

FIGURE 11: Comparison between the multibladder-type inflatable anchor and conventional grouting anchor. 
anchor, the pretension construction method can be applied except for adjusting bladder parameters, which can be investigated by subsequent experimental research studies.

\section{Conclusion}

In this study, the field pullout experiments under various bladder parameter collocation modes were executed, and the influence of bladder parameters (length, space, number, thickness, and diameter) on the bearing capacity and deformation control of the multibladder-type inflatable anchor was explored and discussed via analyzing the pulling resistance vs. displacement curves. The following conclusions were obtained:

(1) According to the field geological conditions, the design and implementation scheme of the whole field experiment process of the multibladder-type inflatable anchor was introduced in detail, including the field soil condition, the facilities' preparation, and the construction technology, refining and perfecting the technological process of the application of the multibladder-type inflatable anchor.

(2) With the increase of bladder parameters, the ultimate pulling resistances are all improved, but the increasing magnitude varies, wherein the increasing magnitudes of bladder length, number, and space are inconspicuous, while the others are significant. With respect to ultimate displacement, all the bladder parameters show positive effects to the displacement control of the multibladder-type inflatable anchor in soft soil, except bladder length.

(3) A comprehensive comparison on the working characteristics in soft soil between the multibladdertype inflatable anchor and conventional grouting anchor was made by field pullout experiments, and the results show that the ultimate pulling resistance and displacement of the former are 1.37 and 1.17 times to those of the latter, proving that the multibladder-type inflatable anchor is better at improving bearing capacity of the anchor. The research findings provide a reasonable and effective reference basis for the follow-up theoretical research.

\section{Data Availability}

The data used to support the findings of this study are available from the corresponding author upon request.

\section{Conflicts of Interest}

The authors declare that they have no conflicts of interest.

\section{Acknowledgments}

This research was funded by Guangzhou Science, Technology and Innovation Commission (201803030009). The authors wish to acknowledge the support.

\section{References}

[1] M. Wang, W. Wan, and Y. Zhao, "Experimental study on crack propagation and the coalescence of rock-like materials with two preexisting fissures under biaxial compression," Bulletin of Engineering Geology and the Environment, vol. 79, no. 6, pp. 3121-3144, 2020.

[2] H. Lin, Y. Zhu, J. Yang, and Z. Wen, "Anchor stress and deformation of the bolted joint under shearing," Advances in Civil Engineering, vol. 2020, Article ID 3696489, 10 pages, 2020.

[3] J. Shen, "Experimental study on anchorage performance of resin grout with steel segment," Advances in Civil Engineering, vol. 2021, Article ID 5580555, 19 pages, 2021.

[4] B. Wu, X. Wang, J. Bai, S. Liu, G. Wang, and G. Li, "A study of the anchorage body fracture evolution and the energy dissipation rule: comparison between tensioned rock bolts and torqued rock bolts," Advances in Civil Engineering, vol. 2021, Article ID 5542569, 14 pages, 2021.

[5] L. Lutz and P. Gergeley, "Mechanics of band and slip of deformed bars in concrete," Journal of the American Concrete Institute, vol. 64, pp. 711-722, 1967.

[6] K. Kovári, "History of the sprayed concrete lining methodpart I: milestones up to the 1960s," Tunnelling and Underground Space Technology, vol. 18, no. 1, pp. 57-69, 2003.

[7] P. G. Fuller and R. H. T. Cox, "Mechanics of load transfer from steel tendons to cement based grout," International Journal of Rock Mechanics and Mining Science \& Geomechanics Abstracts, vol. 14, no. 3, p. 52, 1977.

[8] W. Yuan, Z. Li, J. Niu, W. Wang, and J. Li, "Research on a twoparameter reduction method that strictly satisfies the upper and lower limit theorem," Bulletin of Engineering Geology and the Environment, vol. 79, no. 6, pp. 2937-2947, 2020.

[9] Y. Wei, L. Jiaxin, L. Zonghong, W. Wei, and S. Xiaoyun, “A strength reduction method based on the Generalized HoekBrown (GHB) criterion for rock slope stability analysis," Computers and Geotechnics, vol. 117, Article ID 103240, 2020.

[10] X. Zhang, H. Lin, Y. Wang, R. Yong, Y. Zhao, and S. Du, "Damage evolution characteristics of saw-tooth joint under shear creep condition," International Journal of Damage Mechanics, vol. 30, no. 3, pp. 453-480, 2021.

[11] Y. Chen, H. Lin, X. Ding, and S. Xie, "Scale effect of shear mechanical properties of non-penetrating horizontal rocklike joints," Environmental Earth Sciences, vol. 80, no. 5, p. 192, 2021.

[12] Y. Chen, H. Lin, R. Cao, and C. Zhang, "Slope stability analysis considering different contributions of shear strength parameters," International Journal of Geomechanics, vol. 21, Article ID 04020265, 2021.

[13] C. Zhang, Y. Wang, and T. Jiang, "The propagation mechanism of an oblique straight crack in a rock sample and the effect of osmotic pressure under in-plane biaxial compression," Arabian Journal of Geosciences, vol. 13, no. 15, p. 736, 2020.

[14] Y. Zhao, L. Zhang, J. Liao, W. Wang, Q. Liu, and L. Tang, "Experimental study of fracture toughness and subcritical crack growth of three rocks under different environments," International Journal of Geomechanics, vol. 20, Article ID 04020128, 2020.

[15] Y. Zhao, Y. Wang, W. Wang, L. Tang, Q. Liu, and G. Cheng, "Modeling of rheological fracture behavior of rock cracks subjected to hydraulic pressure and far field stresses," Theoretical and Applied Fracture Mechanics, vol. 101, pp. 59-66, 2019. 
[16] Y. Zhao, Y. Wang, W. Wang, W. Wan, and J. Tang, "Modeling of non-linear rheological behavior of hard rock using triaxial rheological experiment," International Journal of Rock Mechanics and Mining Sciences, vol. 93, pp. 66-75, 2017.

[17] H. P. Kang and J. H. Wang, Theory and Technology of Bolt Support in Coal Roadway, Coal Industry Press, Beijing, China, 2007.

[18] Y. W. Shi, Control Technology of Rock Strata in Deep Mining of Coal Mines at Home and Abroad, Coal Industry Press, Beijing, China, 2009.

[19] T. J. Freeman, "The behavior of fully bonded rock bolts in the kielder experimental tunnel," Tunnels \& Tunnelling.vol. 10, pp. 37-40, 1978.

[20] C. C. Li, G. Kristjansson, and A. H. Høien, "Critical embedment length and bond strength of fully encapsulated rebar rockbolts," Tunnelling and Underground Space Technology, vol. 59, pp. 16-23, 2016.

[21] L. P. Srivastava and M. Singh, "Empirical estimation of strength of jointed rocks traversed by rock bolts based on experimental observation," Engineering Geology, vol. 197, pp. 103-111, 2015.

[22] C. J. Haas, "Shear resistance of rock bolts," Transactions of the Society of Mining Engineers of AIME;(United States), vol. 260, no. 1, pp. 32-41, 1976.

[23] N. R. Barton, "Bolt design based on shear strength," in Proceeding of the International Conference on Rock Joints, Abisko, Sweden, January 1983.

[24] B. Yuan, L. Xiong, L. Zhai et al., "Transparent synthetic soil and its application in modeling of soil-structure interaction using optical system," Frontiers of Earth Science, vol. 7, 2019.

[25] B. Yuan, M. Sun, Y. Wang, L. Zhai, Q. Luo, and X. Zhang, "Full 3D displacement measuring system for 3D displacement field of soil around a laterally loaded pile in transparent soil," International Journal of Geomechanics, vol. 19, Article ID 04019028, 2019.

[26] B. Yuan, K. Xu, Y. Wang, R. Chen, and Q. Luo, "Investigation of deflection of a laterally loaded pile and soil deformation using the PIV technique," International Journal of Geomechanics, vol. 17, 2017.

[27] B. Bai, W. Yuan, and X.-c. Li, "A new double reduction method for slope stability analysis," Journal of Central South University, vol. 21, no. 3, pp. 1158-1164, 2014.

[28] W. Yuan, B. Bai, X. Li, and H. Wang, "A strength reduction method based on double reduction parameters and its application," Journal of Central South University, vol. 20, no. 9, pp. 2555-2562, 2013.

[29] H. Lin, P. Sun, Y. Chen, Y. Zhu, X. Fan, and Y. Zhao, "Analytical and experimental analysis of the shear strength of bolted saw-tooth joints," European Journal of Environmental and Civil Engineering, vol. 24, pp. 1-15, 2020.

[30] K. Huang, Y. Sun, X. Huang, Y. Li, M. Jiang, and R. Liu, "Effects of different construction sequences on ground surface settlement and displacement of single long pile due to twin paralleled shield tunneling," Advances in Civil Engineering, vol. 2021, Article ID 5559233, 14 pages, 2021.

[31] Y. Zhao, H. Zhang, and Y. Nie, "Study of shear capacity of jointed rock mass with prestressed anchor bolt," Advances in Civil Engineering, vol. 2019, Article ID 6824543, 10 pages, 2019.

[32] W. X. Peng and J. W. Cao, “A review of studies on inflatable anchor," Tech review, vol. 28, pp. 111-115, 2010.

[33] T. S. Gallacher, Novel Anchoring Systems for Remotely Operated Vehicles, Dundee University, England, 2000.
[34] T. A. Newson, F. W. Smith, and P. Brunning, "An experimental study of inflatable offshore anchors," in Proceeding of the ISOPE2003 Conference, pp. 345-356, Honolulu, Hawaii, USA, May 2003.

[35] W. X. Peng, M. K. Xu, Y. F. Chen, Z. H. Chen, and Z. Yang, "Field experiment research of the polycystic aeration bolt: model design and anchorage mechanism," Advances in Civil Engineering, vol. 2021, Article ID 6669368, 10 pages, 2021.

[36] Z. M. Jiang, C. J. Wang, and T. He, "Design and performance analysis of yielding anchor bolt with large deformation," Applied Mechanics and Materials, vol. 215-216, pp. 21-26, 2012.

[37] B. Wang, J. Wang, and D. X. Wu, "Study of application of yielding supporting system for largedeformation in soft rock highway tunnel," Journal of railway science and engineerin, vol. 13, p. 1985, 2016.

[38] J. Q. Wang, The Engineering Test about a New Kind of Hot Melting Recoverable Anchor Rope with Pressure Dispersion Type, Guangzhou University, Guangzhou, China, 2015.

[39] W. X. Peng, X. Zhang, J. J. Mo, Y. Y. Huang, and Y. Q. Quan, "Model test study on bladder-type inflatable anchor," Journal of Hunan University, vol. 42, pp. 93-99, 2015.

[40] W. X. Peng and Z. H. Chen, "Research on anchorage theory of the multi-bladder-type inflatable anchor," Technology Innovation and Application, vol. 15, pp. 22-25, 2019.

[41] W. X. Peng and B. Yuan, "Design and manufacture of a bladder-type inflatable anchor in engineering application," Value Engineering, vol. 39, pp. 185-187, 2020.

[42] X. Yang, S. Jia, C. Wen, and Y. Liu, "Development of a new inflatable controlled anchor system and experimental study of pull-out capacity," Advances in Civil Engineering, vol. 2019, Article ID 8105986, 12 pages, 2019.

[43] X. X. Yang, Y. Fa Jiao, and Y. Y. Yang, "Development and test of aerated inflation controlled anchors," Rock and Soil Mechanics, vol. 41, pp. 869-876, 2020.

[44] S. Z. Zhang, "Research on reliability of active drill pipe for automatic drilling rig," Coal Mine Machinery, vol. 40, pp. 37-39, 2019.

[45] X. Q. Ma, Experimental Study on Bearing Capacity and Group Anchor Effect of Inflatable Anchors in Clay, Hunan University of Science and Technology, Xiangtan, China, 2017.

[46] Q. Cui, M. Xing, W. Z. Yang, and S. J. Ding, "Field pull-out test and design method of the short pile and anchor composite foundation in the Karst area," Chinese Journal of Rock Mechanics and Engineering, vol. 37, pp. 2621-2630, 2018.

[47] G. Guo, Z. Liu, Y. K. Li, S. Yang, and Y. Zhang, "Model test research on failure mechanism of underreamed ground anchor Chinese," Journal of Rock Mechanics and Engineering, vol. 32, pp. 1677-1684, 2013. 